\title{
Vagus Nerve Stimulation in the Treatment of Refractory Epilepsy
}

\author{
Andrew H. Milby, Casey H. Halpern, and Gordon H. Baltuch \\ Department of Neurosurgery, Center for Functional and Restorative Neurosurgery, University of Pennsylvania Medical Center, \\ Philadelphia, Pennsylvania 19104
}

\begin{abstract}
Summary: Many patients with epilepsy suffer from persistent seizures despite maximal anti-epileptic drug therapy. Chronic, intermittent vagus nerve stimulation has been proven to be an effective option for many patients suffering from refractory seizures who are not candidates for surgical resection. Although only a small minority of patients will be entirely seizure-free, vagus nerve stimulation, as an ad-
\end{abstract}

junct to medical therapy, may result in significant improvements in quality of life. Vagus nerve stimulation is generally well-tolerated, as device implantation is associated with a low rate of perioperative complications, and the majority of side effects are stimulation-dependent and thus reversible. Key Words: Vagus nerve stimulation, vagal, epilepsy, seizure.

\section{VAGUS NERVE STIMULATION FOR EPILEPSY}

Approximately one third of epileptic patients will suffer from refractory seizures despite maximal anti-epileptic drug (AED) therapy, or they will experience unacceptable side effects of their medications. Surgical resection, such as temporal lobectomy for mesial temporal sclerosis, can result in a dramatic reduction in seizure frequency in select patients; however, surgery carries significant risks of permanent neurologic deficits and even death, with reports of operative mortality reaching $3.6 \%$ at some centers. ${ }^{1}$

Vagus nerve stimulation (VNS) remains the only nonexperimental surgical option available for patients who need surgical management but are reluctant to undergo an intracranial procedure. Moreover, as many as $40 \%$ of patients are not candidates for surgical resection. ${ }^{2}$ The neurocybernetic prosthesis (NCP) system developed by Cyberonics (Webster, TX) was approved by the United States Food and Drug Administration in 1997 as an adjunct to pharmacotherapy for adults and adolescents $\left(>12\right.$ years of age) with refractory partial onset seizures. ${ }^{3,4}$ Here, we review the Cyberonics device, implantation procedure, possible mechanisms of action of VNS-in-

Address correspondence and reprint requests to: Gordon Baltuch, M.D., Ph.D., F.R.C.S.C., Department of Neurosurgery, 3 Silverstein, Hospital of the University of Pennsylvania, 3400 Spruce Street, Philadelphia, PA 19104.E-mail: Gordon.Baltuch@uphs.upenn.edu. duced seizure suppression, results from efficacy studies, and commonly reported adverse events.

\section{NCP System: Device and Surgical Procedure}

The NCP system consists primarily of the NCP generator and lead (FIG. 1). The NCP generator delivers intermittent stimulation with set parameters, including output current, frequency, pulse width, stimulation ontime, and stimulation off-time. Programmed parameters can be adjusted by a clinician to maximize overall benefit using the external NCP programming wand and software. In addition, a hand-held magnet can be used by patients or caregivers to activate VNS in response to an aura or seizure onset.

A number of variations on the operative technique of VNS implantation have been described. ${ }^{3-10}$ Additional details regarding the surgical procedure have been published previously. ${ }^{11}$ Due to potentially higher risks of bradycardia and arrhythmias with right VNS, the left vagus nerve has been targeted in the majority of cases. ${ }^{2,13}$ However, a recent report of right-sided VNS in children may call this claim into question. ${ }^{14}$ Briefly, typically under general anesthesia, a transverse incision is made at the level of the cricothyroid membrane along the anterior edge of the left sternocleidomastoid muscle. Dissection is performed medial to the sternocleidomastoid muscle, and the inferior cervical vagus nerve is identified in a posterior groove of the carotid sheath. Three centimeters of the nerve are exposed for device implantation. Next, an infraclavicular subcutaneous 


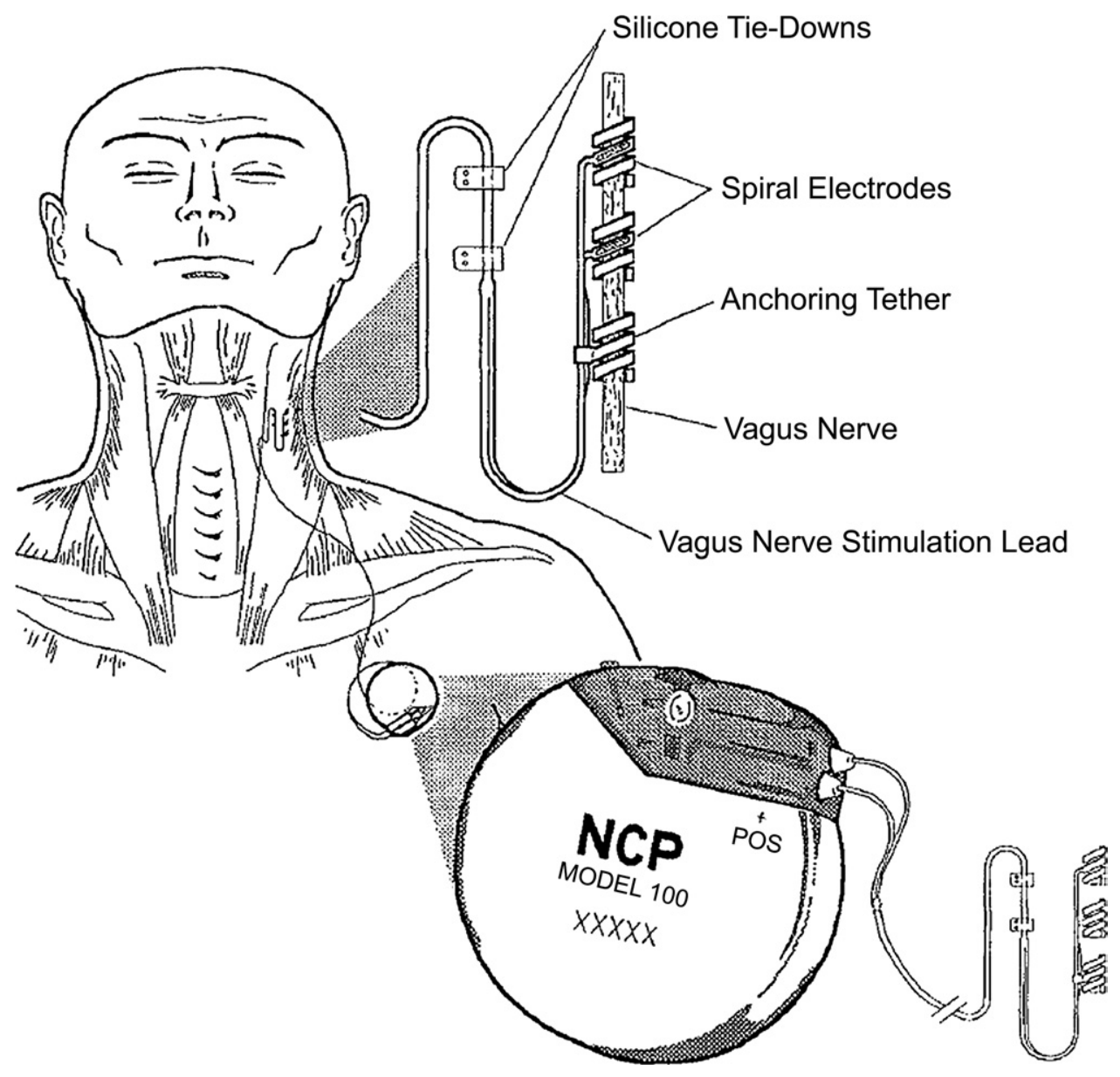

FIG. 1. The neurocybernetic prosthesis generator and lead.

pocket is made for placement of the NCP generator. The VNS lead connector is then tunneled subcutaneously to attach to the NCP generator. Two helical bipolar stimulating electrodes, as well as an anchor tether, are then carefully wrapped around the left vagus nerve, distal to the superior laryngeal nerve and the superior and inferior cervical cardiac branches. ${ }^{15}$ Of particular concern is the potential for bradycardia and even complete heart block in as many as 3\% of patients during initial electrode placement and testing. ${ }^{16-19}$ The risk of this complication can be minimized by ensuring proper positioning and orientation of the electrode on the nerve and the connector pins in the pulse generator. Intraoperative electrocardiographic monitoring is also recommended during the initial electrode test, and the surgical team should be prepared for advanced cardiac life support if clinically indicated.

The output current is initially set at zero $(0 \mathrm{~mA})$ for the first 2 weeks, followed by titration of stimulation to individual patient response. Beginning parameter settings of $30-\mathrm{Hz}$ signal frequency, $500-\mu$ s pulse width, $30 \mathrm{~s}$ on-time, and 5 minutes off-time have been found to be effective in double-blind, controlled studies, although these parameters may vary considerably in practice. ${ }^{20,21}$ Incremental increases in output current of 0.25 to $0.5 \mathrm{~mA}$ every 2 to 4 weeks allow for gradual acclimation, and may ultimately increase a patient's tolerance for higher output current if required for optimal seizure control. ${ }^{22}$

\section{Rationale and proposed mechanisms of VNS in epilepsy control}

Despite its traditional designation as a parasympathetic efferent, the vagus nerve has a mixed composition, with approximately $20 \%$ efferent and $80 \%$ afferent fibers. The afferent fibers originate in the jugular and nodose ganglia and innervate the nucleus tractus solitarius bilaterally, sending projections to various regions associated with seizure activity. ${ }^{23}$ They are comprised largely of smalldiameter, unmyelinated $\mathrm{C}$ fibers, but also contain smaller numbers of larger-diameter, myelinated A fibers and B fibers. ${ }^{24}$ It is by stimulation of these afferent fibers that VNS attempts to remotely exert its antiseizure effects on intracranial structures; however, the mechanisms of these effects are largely unknown. Current research is focused on identifying the afferent fiber types that are involved, characterizing altered patterns of cerebral metabolism or 
activation with functional neuroimaging or electroencephalography (EEG), and measuring stimulation-responsive neurotransmitters known to modulate seizure activity.

The reduction and/or prevention of pharmacologicallyinduced seizures by stimulation of $\mathrm{C}$ fibers in rats led to the initial conclusion that $\mathrm{C}$ fibers figured prominently into the mechanism of VNS. ${ }^{25}$ However, this finding was called into question by the observation that the clinical efficacy of VNS in humans was maintained at stimulation parameters thought not to exceed the threshold necessary for $\mathrm{C}$ fiber activation. ${ }^{26} \mathrm{~A}$ subsequent study in rats observed that the VNS-induced seizure suppression remained intact, despite selective destruction of $\mathrm{C}$ fibers with capsaicin. ${ }^{27}$ Further investigation in this area is necessary to determine which afferent fiber types mediate the effects of VNS.

Many thalamic nuclei contain thalamocortical relay neurons with broad projections ${ }^{28}$ that may modulate propagation of seizure activity. ${ }^{29}$ The anti-epileptic effects of VNS may be explained in part by changes in trans-synaptic neurotransmission, as reflected by altered thalamic cerebral blood flow. Positron emission tomography has shown that VNS increases bilateral thalamic blood flow, which positively correlates with seizure responsiveness. ${ }^{30}$ These findings have been supported by single-photon emission computed tomography showing altered cerebral blood flow patterns in the thalamus that also correlate with clinical efficacy. ${ }^{31}$ Thus, VNS-induced modulation of thalamic synaptic activity may contribute to reductions in seizure frequency or severity.

The EEG effects of VNS have been best documented in animal studies, which have demonstrated cortical synchronization or desynchronization, dependent on stimulus frequency and intensity. ${ }^{32,33}$ High-intensity, high-frequency $(>70 \mathrm{~Hz})$ VNS produced desynchronization of the cortical EEG in cats, but lower intensity VNS at the same frequency resulted in synchronization. These intensity-specific effects led to the hypothesis that by using careful adjustment of stimulation parameters, VNS may be able to disrupt epileptiform activity by desynchronizing interconnected cortical regions implicated in seizure activity. ${ }^{34}$ VNS has also been found to produce a variety of EEG changes throughout the sleep-wake cycle in cats, and persistent changes observed during periods of slowwave sleep in the absence of stimulation suggest that VNS may mediate its long-term effects via induced neuronal plasticity. ${ }^{35}$ In contrast, VNS has not been shown to produce acute EEG changes in humans. One long-term pilot study observed a decrease in spikes per time interval over 12 months of VNS, but other findings of synchronization or clustering were not consistently observed. ${ }^{36}$ This EEG finding in the setting of long-term VNS could also potentially correlate with the clinical observation that seizure control appears to improve over time ${ }^{37-39}$ but overall the effects of VNS in humans have largely eluded characterization via scalp EEG monitoring.

Neurochemical studies have shown altered concentrations of several amino acids and neurotransmitters, such as ethanolamine in human CSF and brain specimens in response to VNS. ${ }^{40,41}$ This may be an indication of increased amino-acid turnover and increased neuronal activity in regions such as the locus coeruleus. ${ }^{42}$ Moreover, the finding that norepinephrine depletion in the rat locus coeruleus completely abolished the seizure-suppressive effect of VNS further supports the role of this region in seizure propagation. ${ }^{43}$ The observation of increased $c$-fos expression in response to acute and chronic VNS in rats also supports the role of locus coeruleus activation in the acute phase, along with long-term activation of the NTS, paraventricular nucleus of the hypothalamus, parabrachial nucleus, ventral bed nucleus of the stria terminalis, cingulate cortex, and dorsal raphe nucleus. ${ }^{44}$ A marginal decrease in CSF aspartate with 3 months of VNS is also of interest, given the excitatory properties of aspartate. ${ }^{41}$ Indeed, decreased levels of excitatory neurotransmitters may be one factor in the mechanisms underlying improved seizure control. $^{45}$

\section{Clinical outcome of VNS in adults with refractory epilepsy}

Considerable clinical evidence exists to support a role for VNS in seizure prevention and amelioration in adults whose seizures have proven refractory to maximal AED therapy (Table 1). Despite these promising results, VNS in its current form is not a curative treatment for epilepsy. Potential additional benefits of VNS include reduction of AED dosage and toxicity, as well as reduced frequency of epilepsy-related hospitalizations; however, it is important to communicate realistic expectations of efficacy prior to implantation. Optimal seizure control can take months to occur, and may require extensive, individualized parameter adjustment over time.

Preliminary results of pilot studies demonstrated significant reduction in the frequency, intensity, and duration of seizures with chronic, intermittent VNS, ${ }^{6,7,46-49}$ which led to subsequent multicenter, double-blinded, randomized controlled trials in adults with medically refractory epilepsy. ${ }^{8,21,50,51}$ These trials demonstrated a mean or median seizure frequency reduction of 24 to $31 \%$ over 3 months of follow-up in patients receiving the high VNS treatment paradigm (i.e., VNS at therapeutic stimulatory parameters, such as $30 \mathrm{~Hz}, 30 \mathrm{~s}$ on, 5 min off, and 500-ks pulse width). This improvement was significantly greater than that found in patients in the low or subtherapeutic VNS group (e.g., $1 \mathrm{~Hz}, 30 \mathrm{~s}$ on, 90-180 min off, 1.30-ks pulse width); these patients experienced a mean or median seizure frequency reduction of only 6 to $15 \%$. In fact, one trial noted a $6 \%$ median increase in 
TABLE 1. Clinical Outcome of Vagus Nerve Stimulation for Refractory Seizures

\begin{tabular}{|c|c|c|c|c|}
\hline Series & $\mathrm{N}$ & Mean Age (y) & Follow-up, $(\mathrm{mo})^{*}$ & $\begin{array}{l}\text { Percentage Change in Total Seizure } \\
\text { Frequency From Baseline }{ }^{\dagger}\end{array}$ \\
\hline Handforth et al..$^{51}(1998)^{\ddagger \S}$ & 102 & 34 & $3-4$ & -15.2 \\
\hline Handforth et al. ${ }^{51}(1998)^{\ddagger}$ & 94 & 32 & $3-4$ & -27.9 \\
\hline Ben-Menachem et al. ${ }^{21}(1994)^{\ddagger \S}$ & 36 & 35 & 3.5 & -11.3 \\
\hline Ben-Menachem et al. $^{21}(1994)^{\ddagger \|}$ & 31 & 34 & 3.5 & -30.9 \\
\hline George et al. ${ }^{20}(1994)^{\mathrm{II}}$ & 67 & 35 & $16-18$ & -52 \\
\hline Hornig et al. ${ }^{63}$ (1997) & 19 & 12 & 30 & -53.2 \\
\hline Penry and Dean ${ }^{7}(1990)$ & 4 & 29-39 & 8.5 & -60 \\
\hline Uthman et al. ${ }^{46}(1990)$ & 5 & $20-59$ & 6 & -25.8 \\
\hline Uthman et al. ${ }^{6}$ (1993) & 14 & 32 & $3.5-8.75$ & -46.6 \\
\hline Landy et $\mathrm{l}^{8} .^{8}(1993)^{\ddagger \S}$ & 5 & $22-55$ & $3-4.25$ & 12.8 \\
\hline Landy et al. ${ }^{8}(1993)^{\ddagger \|}$ & 4 & $22-55$ & $3-4.25$ & -23.1 \\
\hline VNS Study Group ${ }^{50}(1995)^{\ddagger}$ & 60 & 33.5 & 3 & -6.1 \\
\hline VNS Study Group ${ }^{50}(1995)^{\ddagger}$ & 54 & 33.1 & 3 & -24.5 \\
\hline Salinsky et al. ${ }^{53}(1996)^{\mathrm{II}}$ & 100 & 33.3 & $10-12$ & -32 \\
\hline Labar et $\mathrm{al}^{49}(1998)$ & 5 & 30.2 & 9 & -41 \\
\hline Lundgren et al. ${ }^{38}$ (1998) & 16 & 11 & $2.5-3$ & -26 \\
\hline Boon et al. ${ }^{60}$ (1999) & 15 & 29 & 24 & -42.9 \\
\hline Vonck et al. $^{39}$ (1999) & 25 & 30 & 29 & -42.9 \\
\hline Hosain et al. ${ }^{66}(2000)$ & 13 & 16.7 & 6 & -52 \\
\hline Wakai and Kotagal ${ }^{92}$ (2001) & 5 & 12.3 & 7.5 & -73 \\
\hline Farooqui et al. ${ }^{93}(2001)$ & 5 & 11 & 6.5 & -81 \\
\hline Frost et al. ${ }^{67}(2001)$ & 50 & 13 & 6 & 57.9 \\
\hline Scherrmann et la. $^{56}$ (2001) & 95 & 34.9 & 16 & -30 \\
\hline Majoie et al. ${ }^{94}(2005)$ & 16 & 11 & 6 & -26.9 \\
\hline Helmers et al. ${ }^{95}$ (2001) & 56 & 12 & 6 & -44.7 \\
\hline Aldenkamp et al. ${ }^{96}$ (2002) & 19 & 11.2 & 24 & -20.6 \\
\hline Kawai et al. ${ }^{55}$ (2002) & 13 & 27 & 48 & -63 \\
\hline Chavel et al. ${ }^{97}(2003)$ & 23 & 32 & 24 & -40.7 \\
\hline Hui et al $^{.98}(2004)$ & 13 & 25 & 18 & -40 \\
\hline Holmes et al. ${ }^{99}(2004)^{\#}$ & 16 & 36 & $3-5.25$ & -43.3 \\
\hline $\operatorname{Labar}^{58}(2004)$ & 269 & 32 & 12 & -58 \\
\hline Spanaki et al. ${ }^{57}$ (2004) & 28 & 35 & $60-84$ & -72 \\
\hline Huf et al. ${ }^{100}(2005)$ & 38 & 36.6 & 24 & -26 \\
\hline Hallböök et al. ${ }^{73}$ (2005) & 15 & 11 & 9 & -63 \\
\hline Alexopoulos et al. ${ }^{64}(2006)$ & 16 & 12.1 & 36 & -74 \\
\hline Rychlicki et al. ${ }^{101}$ (2006) & 15 & 11.5 & 36 & -71 \\
\hline Saneto et al. ${ }^{102}(2006)$ & 43 & 8 & 18 & -84 \\
\hline Ardesch et al. ${ }^{103}(2007)$ & 7 & $17-46$ & 72 & -50 \\
\hline De Herdt et al. ${ }^{104}$ (2007) & 138 & 30 & 44 & -51 \\
\hline Kostov et al. ${ }^{105}$ (2007) & 12 & 31 & 23 & -62 \\
\hline Amar et al. ${ }^{106}(2008)^{\alpha}$ & 921 & 28 & 24 & -50.5 \\
\hline Amar et al. ${ }^{106}(2008)^{\beta}$ & 3822 & 26 & 24 & -66.7 \\
\hline McGlone et al. ${ }^{62}(2008)$ & 16 & 35 & 12 & -13.3 \\
\hline Sherman et al. ${ }^{74}$ (2008) & 34 & 12.3 & 12 & -51.2 \\
\hline Rossignol et al. ${ }^{107}$ (2009) & 28 & $3.5-21$ & 24 & -54.8 \\
\hline
\end{tabular}

*We report the longest follow-up period performed in each study when noted; otherwise we report mean or median follow-up times.

${ }^{\dagger}$ We report the mean (or median) reduction in seizure frequency at the longest follow-up period reported, unless only the overall reduction in mean monthly seizure frequency is reported.

${ }^{\ddagger}$ Randomized controlled trial.

${ }^{\S}$ Low VNS group: subtherapeutic stimulation parameters.

"High VNS group: therapeutic stimulation parameters.

${ }^{\text {II }}$ All patients in this trial received high VNS having already exited a randomized controlled trial (Ben-Menachem et al., ${ }^{21}$ VNS Study Group, ${ }^{46}$ and Handforth et al. ${ }^{51}$ ).

${ }^{\#}$ This study included only patients with pharmacoresistant generalized epilepsy syndromes.

${ }^{\alpha}$ Prior cranial surgery for epilepsy group.

${ }^{\beta}$ No prior cranial surgery for epilepsy group.

seizure frequency with low VNS. ${ }^{8}$ There were also significant differences in the percentage of patients considered responders ( $\geq 50 \%$ reduction in seizure frequency), consisting of 22 to $39 \%$ of patients in the high VNS group versus only 13 to $19 \%$ of those in the low VNS group. 
The use of the hand-held magnet by patients and caregivers to activate the NCP generator directly in response to auras or simple-partial seizures has also reduced the severity of evolving seizures. According to one study, $21 \%$ of seizures were reported as aborted with use of the hand-held magnet among patients with therapeutic levels of VNS, compared with only $9 \%$ for patients in the low VNS group; a difference that reached statistical significance. In addition, $60 \%$ of seizures in the high VNS group were reported as improved when the magnet was used, compared with $40 \%$ in the low VNS group, suggesting a moderate but significant benefit over what could be considered equivalent to placebo. ${ }^{21}$ Of note, a post hoc analysis of patients at therapeutic stimulation levels showed that the presence of an aura prior to seizure onset was not required or predictive of efficacy in VNS. $^{51}$

After exiting the blinded portion of these trials, all patients were converted to therapeutic levels of VNS and were followed-up for as long as 18 months. ${ }^{20,52,53}$ The percent change in mean seizure frequency relative to baseline was significant for all follow-up periods of VNS, and it was associated with a significant incremental decrease in seizure frequency in the long term. These findings were reinforced by an open-label efficacy trial that enrolled 454 patients from previous randomized, controlled trials, showing sustained median seizure frequency reductions relative to baseline over 3 years of follow-up. Continuation rates of VNS were $97 \%$ at 1 year, $85 \%$ at 2 years, and $72 \%$ at 3 years, demonstrating a high level of overall tolerability and patient satisfaction. 54

As more long-term, follow-up data on the use of VNS has become available, many centers have observed seemingly cumulative effect on seizure suppression over time. ${ }^{39,53-56}$ In fact, one study noted that six patients considered to be nonresponders after 12 months of VNS therapy began to experience reductions in seizure frequency 4 to 6 years later. ${ }^{57}$ The mechanisms by which this effect might be mediated remain highly speculative, but appear to be unrelated to changes in AED regimens. ${ }^{58}$ Gradual adjustments to stimulation parameters may be responsible for much of these improvements, although the adjustment process is highly individualized and impedes the direct comparison of parameters between studies. In addition, many parameter adjustments are undertaken not only to improve treatment response but also in an effort to improve tolerability, and it is uncertain as to what extent this balance changes over extended periods of stimulation.

Additional benefits of VNS may include reductions in AED requirements and improvements in overall quality of life (QOL) that do not necessarily correlate with seizure control. One prospective assessment of AED regimens over 13 months of VNS demonstrated reductions in either dosages or number of AEDs in 15 of 21 patients. $^{59}$ These reductions have the potential to diminish both dose-dependent toxicity and costs associated with these medications. Indeed, one cost-benefit analysis has suggested that VNS results in lower net healthcare costs within 2 years of continuous treatment, but this was primarily due in this series to reductions in epilepsyassociated hospitalizations. ${ }^{60}$ QOL is more difficult to assess quantitatively, and the effects of VNS on QOL in adults remain controversial. Significant within-group improvements in subjective measures of seizure relief relative to baseline were observed in one early trial, ${ }^{4}$ and a subsequent 1-year prospective trial reported QOL improvement in $84 \%$ of patients. ${ }^{61}$ However, these findings have been contradicted by a recent case-control study that found no change in QOL over 12 months of VNS. ${ }^{62}$ These results suggest that there is insufficient evidence at this time to make conclusive statements regarding the effects of VNS on QOL in adult epilepsy.

\section{VNS for refractory seizures in the pediatric population}

Experience with VNS in pediatric patients is limited, although studies have shown favorable results in a large proportion $(32-53 \%)$ of patients treated with adjunctive VNS, ranging from 50 to $90 \%$ reductions in seizure frequency at 1 year postoperatively. ${ }^{38,63}$ Long-term, follow-up at 36 months revealed a mean seizure frequency reduction of $74 \% .{ }^{64} \mathrm{VNS}$ does appear to be a potential option for children under the age of Food and Drug Administration-approved indications. A recent report of VNS in children less than 5 years old demonstrated that $83 \%$ of patients had a significant decrease in seizure frequency at 22 months of follow-up. ${ }^{65}$ Atonic seizures were found to best respond to VNS with cessation in two patients. Indeed, younger patients implanted before the age of 12 years appeared to respond better than the older group of pediatric patients. ${ }^{64}$ Notably, children with Lennox-Gastaut syndrome have been shown to respond very favorably to $\mathrm{VNS}^{66,67}$ The efficacy of VNS appears to compare favorably to corpus callosotomy in these patients. ${ }^{68}$ Other studies have demonstrated similar seizure reduction in tuberous sclerosis complex. ${ }^{69}$ VNS has also been successful in refractory nonconvulsive status epilepticus, facilitating prolonged seizure reduction, and partial AED tapering. ${ }^{70,71}$ In contrast to such promising applications, preliminary evidence suggests that VNS is not effective for seizure control or cognitive improvement in patients with comorbid autistic spectrum disorders. $^{72}$ Effects of VNS on QOL in children are also controversial, as two series have found strong associations between improved seizure severity and parental conception of QOL, ${ }^{38,73}$ whereas one did not demonstrate a significant effect. ${ }^{74}$ Nonetheless, the wide range of response rates in children emphasizes the need for a 
TABLE 2. Rates of Common Perioperative and Stimulation-Related Adverse Events with VNS for Epilepsy

\begin{tabular}{|c|c|c|c|c|c|c|}
\hline \multirow[b]{2}{*}{ Series } & \multirow[b]{2}{*}{$\mathrm{N}$} & \multirow[b]{2}{*}{ Follow-up Period (mo) } & \multicolumn{4}{|c|}{ Adverse Events, no. (\%) } \\
\hline & & & Infection* & Neck Pain & Other Pain & Voice Alteration \\
\hline & \multicolumn{6}{|c|}{ Epilepsy } \\
\hline Handforth et al. ${ }^{51}$ (1998) (LS) & 103 & $3-4$ & $12(12)$ & & $31(30)$ & $31(30)$ \\
\hline Handforth et al. $^{51}$ (1998) (HS) & 95 & $3-4$ & $11(12)$ & & $27(28)$ & $63(66)$ \\
\hline VNS Study Group $^{50}$ (1995) (LS) & 60 & 3 & & $7(12)$ & $16(27)$ & $1(2)$ \\
\hline VNS Study Group $^{50}$ (1995) (HS) & 54 & 3 & & $6(11)$ & $16(30)$ & $3(6)$ \\
\hline Labar et al. ${ }^{49}(1998)$ & 5 & 9 & $1(20)$ & & & $1(20)$ \\
\hline Lundgren et al. $^{38}$ (1998) & 16 & $2.5-3$ & & $1(6)$ & & $6(38)$ \\
\hline Vonck et al. $^{39}$ (1999) & 15 & 29 & & & & $2(13)$ \\
\hline Hosain et al. ${ }^{66}(2000)$ & 13 & 6 & $1(8)$ & $3(23)$ & & $3(23)$ \\
\hline Wakai and Kotagal ${ }^{92}$ (2001) & 5 & 7.5 & & $5(100)$ & $1(20)$ & $4(80)$ \\
\hline Frost et al. ${ }^{67}(2001)$ & 50 & 6 & $2(4)$ & $5(10)$ & $5(10)$ & $22(44)$ \\
\hline Scherrmann et al. ${ }^{56}$ (2001) & 84 & 16 & $2(2)$ & & & $48(57)$ \\
\hline Majoie et al. ${ }^{94}(2005)$ & 16 & 6 & $0(0)$ & & & $7(44)$ \\
\hline Helmers et al. ${ }^{95}$ (2001) & 56 & 6 & $0(0)$ & & & $32(57)$ \\
\hline Hui et al. ${ }^{98}(2004)$ & 13 & 18 & & $3(23)$ & & \\
\hline Holmes et al. ${ }^{99}$ (2004) & 16 & $3-5.25$ & & $3(19)$ & & $14(88)$ \\
\hline Hallböök et al. $^{73}$ (2005) & 15 & 9 & $0(0)$ & $1(7)$ & & $4(27)$ \\
\hline Alexopoulos et al. ${ }^{64}$ (2006) & 46 & 36 & $5(11)$ & & & \\
\hline Rychlicki et al. ${ }^{101}$ (2006) & 34 & 36 & & $4(12)$ & & $15(44)$ \\
\hline Saneto et al. ${ }^{102}(2006)$ & 63 & 18 & $2(3)$ & & & \\
\hline Kostov et al. ${ }^{105}$ (2007) & 12 & 23 & $0(0)$ & $3(25)$ & $1(8)$ & $3(25)$ \\
\hline Rossignol et al. ${ }^{107}(2009)$ & 28 & 24 & $2(7)$ & & $2(7)$ & \\
\hline
\end{tabular}

Other reported adverse events include ear pain, tooth disorders, insomnia, palpitations, fever, fatigue, hypersalivation, tachycardia, and laryngismus.

$\mathrm{HS}=$ high stimulation; LS = low stimulation.

*Infection as the sole perioperative adverse event. All other adverse events are stimulation-related, with incidence as reported at time of follow-up.

better understanding of appropriate indications for VNS in this population.

\section{ADVERSE EVENTS WITH VNS}

\section{Perioperative}

Generator implantation and electrode placement for epilepsy or depression is generally well tolerated. A large series assessing common complications of VNS reported infections in $7.1 \%$ of cases. ${ }^{75}$ The infection rates reported in individual clinical trials of VNS for both epilepsy and depression are summarized in Table 2. The incidence of electrode fracture is low, and device failure was uncommon in recent trials. ${ }^{8}$ Electrode removal is not required for generator or battery replacement, and the electrode is typically left in place in the event of device, removal except in the setting of infection. If required, electrode removal can be accomplished with minimal risk of nerve injury, even several years after implantation and despite the presence of fibrosis. ${ }^{76}$ Voice alteration is most commonly observed in conjunction with stimulation, but may occur postoperatively as a consequence of improper electrode placement, excessive intraoperative manipulation, device malfunction, or patient-inflicted traction injury. ${ }^{77}$ Severe bradycardia and asystole have been reported during intraoper- ative electrode placement and device testing, but have proven responsive to epinephrine and/or atropine administration, along with brief cardiac compression. ${ }^{78}$ Other uncommon complications in the immediate postoperative period include fluid accumulation in the generator pocket, partial left-sided facial paralysis, and Horner's syndrome. ${ }^{51,56,77,79}$

\section{Stimulation-related}

Rates of common stimulation-induced adverse events are summarized in Table 2. These symptoms are typically experienced transiently during the initial calibration period and are minimized with adjustment of stimulation parameters or diminish in severity with patient acclimation. $^{75,77}$ Of these, voice alteration is most commonly reported during periods of active stimulation, and is likely the result of adduction of the left vocal fold induced by stimulation of the left recurrent laryngeal nerve. ${ }^{80,81}$ This mechanism may also account for the occurrence of some other common adverse events, such as neck or throat pain, dyspnea, and coughing. Vocal fold immobility may occur in some patients during inactive periods due to cumulative damage from chronic, intermittent stimulation, although long-term VNS has not been found to produce histologic evidence of nerve injury. ${ }^{82}$ Preoperative laryngeal electromyography may be useful 
TABLE 2. Continued

\begin{tabular}{|c|c|c|c|c|c|c|c|c|}
\hline \multicolumn{9}{|c|}{ Adverse Events, no. (\%) } \\
\hline Coughing & Dyspnea & Pharyngitis & Dyspepsia & Dysphagiaa & Nausea & Vomiting & Headache & Paresthesia \\
\hline & & & & Epilepsy & & & & \\
\hline $44(43)$ & $11(11)$ & $26(25)$ & $13(13)$ & & $21(20)$ & $14(14)$ & $24(23)$ & $26(25)$ \\
\hline $43(45)$ & $24(25)$ & $33(35)$ & $17(18)$ & & $14(15)$ & $17(18)$ & $23(24)$ & $17(18)$ \\
\hline $5(8)$ & $1(2)$ & & & & & & $5(8)$ & $2(3)$ \\
\hline $4(7)$ & $3(6)$ & & & & & & $1(2)$ & $3(6)$ \\
\hline \multirow[t]{2}{*}{$2(40)$} & $1(20)$ & & & & & & & \\
\hline & $2(13)$ & & & & & & & \\
\hline $3(20)$ & & & & $1(7)$ & & & & \\
\hline \multicolumn{9}{|l|}{$3(23)$} \\
\hline \multicolumn{9}{|l|}{$2(40)$} \\
\hline $15(30)$ & $2(4)$ & & $2(4)$ & $1(2)$ & $2(4)$ & $1(2)$ & & $4(8)$ \\
\hline $3(4)$ & $2(2)$ & & & $3(4)$ & & & & \\
\hline $4(25)$ & & & & $1(6)$ & & & & $2(13)$ \\
\hline $21(38)$ & & & & $1(2)$ & & & & \\
\hline \multicolumn{9}{|l|}{$3(23)$} \\
\hline \multirow[t]{5}{*}{$1(6)$} & & & & $2(13)$ & & & & \\
\hline & $1(7)$ & & & & & & & $1(7)$ \\
\hline & $1(2)$ & & & & & & & \\
\hline & $3(25)$ & & & & & & & $1(8)$ \\
\hline & $1(4)$ & & & $1(4)$ & & & & \\
\hline
\end{tabular}

in identifying patients at risk for long-term vocal fold or phonation abnormalities. ${ }^{83}$ Patients with comorbid obstructive sleep apnea may be at increased risk for apneic episodes during periods of VNS activation while asleep, and preoperative polysomnography in high-risk patients has been advocated. ${ }^{84-86}$ VNS may cause a mild increase in gastric acid output, but does not affect ulcer formation or vital signs. ${ }^{51,77}$ Targeted studies have reported no or minimal effects on cardiovascular parameters during periods of stimulation in patients without underlying heart disease. ${ }^{87,88}$ Outpatient 24-hour Holter monitoring has also failed to demonstrate any clinically significant adverse effects on cardiac rhythm within recommended stimulation parameters. ${ }^{54,89}$ In one series, long-term follow-up of patients with a history of bradycardia during intraoperative lead testing suggests that postoperative reactivation and chronic stimulation are not associated with recurrence. ${ }^{17}$ Despite these findings, a late-onset, stimulation-related bradyarrhythmia has been described presenting as syncopal episodes 2 years after device implantation in a patient with a normal intraoperative lead test. ${ }^{90}$ As a result, it is recommended that patients with a history of intraoperative bradyarrhythmia or asystole undergo continuous electrocardiographic monitoring during postoperative device initialization, and further evaluation with electrocardiographic and/or Holter monitoring is recommended in all patients with symptoms suggestive of a possible arrhythmia. Although sudden, unexplained deaths have occurred in patients undergoing VNS for epilepsy at higher rates than in the general population, rates of sudden, unexplained death and overall mortality have been found to compare favorably to those of other cohorts undergoing treatment for refractory epilepsy. $55,57,91$

\section{CONCLUSION}

Chronic, intermittent VNS as an adjunct to AED, has been well documented as a treatment option for patients with refractory seizures that provides a significant reduction in seizure frequency and severity, as well as an improvement in QOL. VNS is associated with a low rate of perioperative complications, and the majority of side effects are stimulation-dependent and thus reversible. Despite these relative benefits, VNS should not be considered a substitute for intracranial surgery in patients considered good surgical candidates, because in this subgroup the efficacy does not approach that of surgical resection. More than a decade of Food and Drug Administration approval has allowed for the emergence of a well-defined role for VNS in seizure prevention and 
amelioration. Further study is necessary to determine the role of VNS for other potential indications.

\section{REFERENCES}

1. A global survey on epilepsy surgery, 1980-1990: a report by the Commission on Neurosurgery of Epilepsy, the International League Against Epilepsy. Epilepsia 1997;38:249-255.

2. Kwan P, Brodie MJ. Early identification of refractory epilepsy. N Engl J Med 2000;342:314-319.

3. Terry R, Tarver WB, Zabara J. An implantable neurocybernetic prosthesis system. Epilepsia 1990;31(suppl 2):S33-37.

4. Terry RS, Tarver WB, Zabara J. The implantable neurocybernetic prosthesis system. Pacing Clin Electrophysiol 1991;14:86-93.

5. Reid SA. Surgical technique for implantation of the neurocybernetic prosthesis. Epilepsia 1990;31(suppl 2):S38-S39.

6. Uthman BM, Wilder BJ, Penry JK, et al. Treatment of epilepsy by stimulation of the vagus nerve. Neurology 1993;43:1338-1345.

7. Penry JK, Dean JC. Prevention of intractable partial seizures by intermittent vagal stimulation in humans: preliminary results. Epilepsia 1990;31(suppl 2):S40-S43.

8. Landy HJ, Ramsay RE, Slater J, et al. Vagus nerve stimulation for complex partial seizures: surgical technique, safety, and efficacy. J Neurosurg 1993;78:26-31.

9. Ben-Menachem E. Vagus-nerve stimulation for the treatment of epilepsy. Lancet Neurol 2002;1:477-482.

10. Shafique S, Dalsing MC. Vagus nerve stimulation therapy for treatment of drug-resistant epilepsy and depression. Perspect Vasc Surg Endovasc Ther 2006;18:323-327.

11. Milby AH, Halpern $\mathrm{CH}$, Baltuch GH. Vagus nerve stimulation for epilepsy and depression. Neurotherapeutics 2008;5:75-85.

12. Hancock JC, Hoover DB, Hougland MW. Distribution of muscarinic receptors and acetylcholinesterase in the rat heart. J Auton Nerv Syst 1987;19:59-66.

13. Saper CB, Kibbe MR, Hurley KM, et al. Brain natriuretic peptidelike immunoreactive innervation of the cardiovascular and cerebrovascular systems in the rat. Circ Res 1990;67:1345-1354.

14. McGregor A, Wheless J, Baumgartner J, et al. Right-sided vagus nerve stimulation as a treatment for refractory epilepsy in humans. Epilepsia 2005;46:91-96.

15. Tarver WB, George RE, Maschino SE, et al. Clinical experience with a helical bipolar stimulating lead. Pacing Clin Electrophysiol 1992;15:1545-1556.

16. Ali II, Pirzada NA, Kanjwal Y, et al. Complete heart block with ventricular asystole during left vagus nerve stimulation for epilepsy. Epilepsy Behav 2004;5:768-771.

17. Ardesch JJ, Buschman HP, van der Burgh PH, et al. Cardiac responses of vagus nerve stimulation: intraoperative bradycardia and subsequent chronic stimulation. Clin Neurol Neurosurg 2007; 109:849-852

18. Tatum WOT, Moore DB, Stecker MM, et al. Ventricular asystole during vagus nerve stimulation for epilepsy in humans. Neurology 1999;52:1267-1269.

19. Asconape JJ, Moore DD, Zipes DP, et al. Bradycardia and asystole with the use of vagus nerve stimulation for the treatment of epilepsy: a rare complication of intraoperative device testing. Epilepsia 1999;40:1452-1454.

20. George R, Salinsky M, Kuzniecky R, et al. Vagus nerve stimulation for treatment of partial seizures: 3 . Long-term follow-up on first 67 patients exiting a controlled study. First International Vagus Nerve Stimulation Study Group. Epilepsia 1994;35:637643.

21. Ben-Menachem E, Manon-Espaillat R, Ristanovic R, et al. Vagus nerve stimulation for treatment of partial seizures: 1 . A controlled study of effect on seizures. First International Vagus Nerve Stimulation Study Group. Epilepsia 1994;35:616-626.

22. Labiner DM, Ahern GL. Vagus nerve stimulation therapy in depression and epilepsy: therapeutic parameter settings. Acta Neurol Scand 2007;115:23-33.

23. Henry TR. Therapeutic mechanisms of vagus nerve stimulation. Neurology 2002;59:S3-S14.
24. Vonck K, Boon P, Van Roost D. Anatomical and physiological basis and mechanism of action of neurostimulation for epilepsy. Acta Neurochir Suppl 2007;97:321-328.

25. Woodbury DM, Woodbury JW. Effects of vagal stimulation on experimentally induced seizures in rats. Epilepsia 1990;31(suppl 2):S7-S19.

26. Labiner DM, Schwirtz D, Ahern GL, et al. Shorter pulse width of vagus nerve stimulation is as effective in reducing seizure frequency as standard stimulation and is better tolerated. Epilepsia 1999;40(suppl 7):141.

27. Krahl SE, Senanayake SS, Handforth A. Destruction of peripheral C-fibers does not alter subsequent vagus nerve stimulation-induced seizure suppression in rats. Epilepsia 2001;42:586-589.

28. Carpenter MB. Core text of neuroanatomy, 4th ed. 1991: Williams \& Wilkins, Baltimore.

29. Steriade M, Contreras D. Relations between cortical and thalamic cellular events during transition from sleep patterns to paroxysmal activity. J Neurosci 1995;15:623-642.

30. Henry TR, Votaw JR, Pennell PB, et al. Acute blood flow changes and efficacy of vagus nerve stimulation in partial epilepsy. Neurology 1999;52:1166-1173.

31. Vonck K, De Herdt V, Bosman T, et al. Thalamic and limbic involvement in the mechanism of action of vagus nerve stimulation, a SPECT study. Seizure 2008;17:699-706.

32. Zanchetti A, Wang SC, Moruzzi G. The effect of vagal afferent stimulation on the EEG pattern of the cat. Electroencephalogr Clin Neurophysiol 1952;4:357-361.

33. Chase MH, Nakamura $\mathrm{Y}$, Clemente $\mathrm{CD}$, et al. Afferent vagal stimulation: neurographic correlates of induced EEG synchronization and desynchronization. Brain Res 1967;5:236-249.

34. Schachter SC, Saper CB. Vagus nerve stimulation. Epilepsia 1998;39:677-686.

35. Valdes-Cruz A, Magdaleno-Madrigal VM, Martinez-Vargas D, et al. Long-term changes in sleep and electroencephalographic activity by chronic vagus nerve stimulation in cats. Prog Neuropsychopharmacol Biol Psychiatry 2008;32:828-834.

36. Koo B. EEG changes with vagus nerve stimulation. J Clin Neurophysiol 2001;18:434-441.

37. Murphy JV. Left vagal nerve stimulation in children with medically refractory epilepsy. The Pediatric VNS Study Group. J Pediatr 1999;134:563-566.

38. Lundgren J, Amark P, Blennow G, et al. Vagus nerve stimulation in 16 children with refractory epilepsy. Epilepsia 1998;39:809813.

39. Vonck K, Boon P, D'Have M, et al. Long-term results of vagus nerve stimulation in refractory epilepsy. Seizure 1999;8:328 334.

40. Hamberger A, Haglid K, Nystrom B, et al. Co-variation of free amino acids in human epileptogenic cortex. Neurochem Res 1993;18:519-25.

41. Ben-Menachem E, Hamberger A, Hedner T, et al. Effects of vagus nerve stimulation on amino acids and other metabolites in the CSF of patients with partial seizures. Epilepsy Res 1995;20: 221-227.

42. Naritoku DK, Terry WJ, Helfert RH. Regional induction of fos immunoreactivity in the brain by anticonvulsant stimulation of the vagus nerve. Epilepsy Res 1995;22:53-62.

43. Krahl SE, Clark KB, Smith DC, et al. Locus coeruleus lesions suppress the seizure-attenuating effects of vagus nerve stimulation. Epilepsia 1998;39:709-714.

44. Cunningham JT, Mifflin SW, Gould GG, et al. Induction of c-Fos and DeltaFosB immunoreactivity in rat brain by vagal nerve stimulation. Neuropsychopharmacology 2008;33:1884-1895.

45. Meldrum B. Amino acid neurotransmitters and new approaches to anticonvulsant drug action. Epilepsia 1984;25(suppl 2):S140S149.

46. Uthman BM, Wilder BJ, Hammond EJ, et al. Efficacy and safety of vagus nerve stimulation in patients with complex partial seizures. Epilepsia 1990;31(suppl 2):S44-S50.

47. Wilder BJ, Uthman BM, Hammond EJ. Vagal stimulation for control of complex partial seizures in medically refractory epileptic patients. Pacing Clin Electrophysiol 1991;14:108-115. 
48. Murphy JV, Hornig G, Schallert G. Left vagal nerve stimulation in children with refractory epilepsy. Preliminary observations. Arch Neurol 1995;52:886-889.

49. Labar D, Nikolov B, Tarver B, et al. Vagus nerve stimulation for symptomatic generalized epilepsy: a pilot study. Epilepsia 1998; 39:201-205.

50. A randomized controlled trial of chronic vagus nerve stimulation for treatment of medically intractable seizures. The Vagus Nerve Stimulation Study Group. Neurology 1995;45:224-230.

51. Handforth A, DeGiorgio CM, Schachter SC, et al. Vagus nerve stimulation therapy for partial-onset seizures: a randomized active-control trial. Neurology 1998;51:48-55.

52. Amar AP, DeGiorgio CM, Tarver WB, et al. Long-term multicenter experience with vagus nerve stimulation for intractable partial seizures: results of the XE5 trial. Stereotact Funct Neurosurg 1999;73:104-108.

53. Salinsky MC, Uthman BM, Ristanovic RK, et al. Vagus nerve stimulation for the treatment of medically intractable seizures. Results of a 1-year open-extension trial. Vagus Nerve Stimulation Study Group. Arch Neurol 1996;53:1176-1180.

54. Morris GL, 3rd, Mueller WM. Long-term treatment with vagus nerve stimulation in patients with refractory epilepsy. The Vagus Nerve Stimulation Study Group E01-E05. Neurology 1999;53: $1731-1735$.

55. Kawai K, Shimizu H, Maehara T, et al. Outcome of long-term vagus nerve stimulation for intractable epilepsy. Neurol Med Chir (Tokyo) 2002;42:481-489; discussion 490.

56. Scherrmann J, Hoppe C, Kral T, et al. Vagus nerve stimulation: clinical experience in a large patient series. J Clin Neurophysiol 2001;18:408-414.

57. Spanaki MV, Allen LS, Mueller WM, et al. Vagus nerve stimulation therapy: 5-year or greater outcome at a university-based epilepsy center. Seizure 2004;13:587-590.

58. Labar D. Vagus nerve stimulation for 1 year in 269 patients on unchanged antiepileptic drugs. Seizure 2004;13:392-398.

59. Tatum WO, Johnson KD, Goff $\mathrm{S}$, et al. Vagus nerve stimulation and drug reduction. Neurology 2001;56:561-563.

60. Boon P, Vonck K, Vandekerckhove T, et al. Vagus nerve stimulation for medically refractory epilepsy; efficacy and cost-benefit analysis. Acta Neurochir (Wien) 1999;141:447-452; discussion 453.

61. McLachlan RS, Sadler M, Pillay N, et al. Quality of life after vagus nerve stimulation for intractable epilepsy: is seizure control the only contributing factor? Eur Neurol 2003;50:16-19.

62. McGlone J, Valdivia I, Penner M, et al. Quality of life and memory after vagus nerve stimulator implantation for epilepsy. Can J Neurol Sci 2008;35:287-296.

63. Hornig GW, Murphy JV, Schallert G, et al. Left vagus nerve stimulation in children with refractory epilepsy: an update. South Med J 1997;90:484-488.

64. Alexopoulos AV, Kotagal P, Loddenkemper T, et al. Long-term results with vagus nerve stimulation in children with pharmacoresistant epilepsy. Seizure 2006;15:491-503.

65. Patwardhan RV, Stong B, Bebin EM, et al. Efficacy of vagal nerve stimulation in children with medically refractory epilepsy. Neurosurgery 2000;47:1353-1357; discussion 1357-1358.

66. Hosain S, Nikalov B, Harden C, et al. Vagus nerve stimulation treatment for Lennox-Gastaut syndrome. J Child Neurol 2000;15: 509-512.

67. Frost M, Gates J, Helmers SL, et al. Vagus nerve stimulation in children with refractory seizures associated with Lennox-Gastaut syndrome. Epilepsia 2001;42:1148-1152.

68. You SJ, Kang HC, Ko TS, et al. Comparison of corpus callosotomy and vagus nerve stimulation in children with LennoxGastaut syndrome. Brain Dev 2008;30:195-199.

69. Major P, Thiele EA. Vagus nerve stimulation for intractable epilepsy in tuberous sclerosis complex. Epilepsy Behav 2008;13:357-360.

70. De Herdt V, Waterschoot L, Vonck K, et al. Vagus nerve stimulation for refractory status epilepticus. Eur J Paediatr Neurol 2008 Jun 26. [Epub ahead of print].

71. Zamponi N, Rychlicki F, Corpaci L, et al. Vagus nerve stimulation (VNS) is effective in treating catastrophic 1 epilepsy in very young children. Neurosurg Rev 2008;31:291-297.
72. Danielsson S, Viggedal G, Gillberg C, et al. Lack of effects of vagus nerve stimulation on drug-resistant epilepsy in eight pediatric patients with autism spectrum disorders: a prospective 2-year follow-up study. Epilepsy Behav 2008;12:298-304.

73. Hallböök T, Lundgren J, Stjernqvist K, et al. Vagus nerve stimulation in 15 children with therapy resistant epilepsy; its impact on cognition, quality of life, behavior and mood. Seizure 2005; 14:504-513.

74. Sherman EM, Connolly MB, Slick DJ, et al. Quality of life and seizure outcome after vagus nerve stimulation in children with intractable epilepsy. J Child Neurol 2008;23:991-998.

75. Smyth MD, Tubbs RS, Bebin EM, et al. Complications of chronic vagus nerve stimulation for epilepsy in children. J Neurosurg 2003;99:500-503.

76. MacDonald J, Couldwell WT. Revision of vagal nerve stimulator electrodes: technical approach. Acta Neurochir (Wien) 2004;146: 567-570; discussion 570.

77. Ramsay RE, Uthman BM, Augustinsson LE, et al. Vagus nerve stimulation for treatment of partial seizures: 2. Safety, side effects, and tolerability. First International Vagus Nerve Stimulation Study Group. Epilepsia 1994;35:627-636.

78. Hatton KW, McLarney JT, Pittman T, et al. Vagal nerve stimulation: overview and implications for anesthesiologists. Anesth Analg 2006;103:1241-1249.

79. Kim W, Clancy RR, Liu GT. Horner syndrome associated with implantation of a vagus nerve stimulator. Am J Ophthalmol 2001; 131:383-384.

80. Lundy DS, Casiano RR, Landy HJ, et al. Effects of vagal nerve stimulation on laryngeal function. J Voice 1993;7:359-364.

81. Zumsteg D, Jenny D, Wieser HG. Vocal cord adduction during vagus nerve stimulation for treatment of epilepsy. Neurology 2000;54:1388-1389.

82. Shaffer MJ, Jackson CE, Szabo CA, et al. Vagal nerve stimulation: clinical and electrophysiological effects on vocal fold function. Ann Otol Rhinol Laryngol 2005;114:7-14.

83. Shaw GY, Sechtem P, Searl J, et al. Predictors of laryngeal complications in patients implanted with the Cyberonics vagal nerve stimulator. Ann Otol Rhinol Laryngol 2006;115:260-267.

84. Ebben MR, Sethi NK, Conte M, et al. Vagus nerve stimulation, sleep apnea, and CPAP titration. J Clin Sleep Med 2008;4:471473.

85. Hsieh T, Chen M, McAfee A, et al. Sleep-related breathing disorder in children with vagal nerve stimulators. Pediatr Neurol 2008;38:99-103.

86. Papathanasion ES, Papacostas SS. Sleep-related breathing disorders in children with vagal nerve stimulators. Pediatr Neurol 2008;39:142.

87. Banzett RB, Guz A, Paydarfar D, et al. Cardiorespiratory variables and sensation during stimulation of the left vagus in patients with epilepsy. Epilepsy Res 1999;35:1-11.

88. Stemper B, Devinsky O, Haendl T, et al. Effects of vagus nerve stimulation on cardiovascular regulation in patients with epilepsy. Acta Neurol Scand 2008;117:231-236.

89. DeGiorgio CM, Schachter SC, Handforth A, et al. Prospective long-term study of vagus nerve stimulation for the treatment of refractory seizures. Epilepsia 2000;41:1195-1200.

90. Amark P, Stodberg T, Wallstedt L. Late onset bradyarrhythmia during vagus nerve stimulation. Epilepsia 2007;48:1023-1024.

91. Annegers JF, Coan SP, Hauser WA, et al. Epilepsy, vagal nerve stimulation by the NCP system, all-cause mortality, and sudden, unexpected, unexplained death. Epilepsia 2000;41:549-553.

92. Wakai S, Kotagal P. Vagus nerve stimulation for children and adolescents with intractable epilepsies. Pediatr Int 2001;43: $61-65$.

93. Farooqui S, Boswell W, Hemphill JM, et al. Vagus nerve stimulation in pediatric patients with intractable epilepsy: case series and operative technique. Am Surg 2001;67:119-121.

94. Majoie HJ, Berfelo MW, Aldenkamp AP, et al. Vagus nerve stimulation in patients with catastrophic childhood epilepsy, a 2-year follow-up study. Seizure 2005;14:10-18.

95. Helmers SL, Wheless JW, Frost M, et al. Vagus nerve stimulation therapy in pediatric patients with refractory epilepsy: retrospective study. J Child Neurol 2001;16:843-848. 
96. Aldenkamp AP, Majoie HJ, Berfelo MW, et al. Long-term effects of 24-month treatment with vagus nerve stimulation on behaviour in children with Lennox-Gastaut syndrome. Epilepsy Behav 2002; 3:475-479.

97. Chavel SM, Westerveld M, Spencer S. Long-term outcome of vagus nerve stimulation for refractory partial epilepsy. Epilepsy Behav 2003;4:302-309.

98. Hui AC, Lam JM, Wong KS, et al. Vagus nerve stimulation for refractory epilepsy: long term efficacy and side-effects. Chin Med J (Engl) 2004;117:58-61.

99. Holmes MD, Silbergeld DL, Drouhard D, et al. Effect of vagus nerve stimulation on adults with pharmacoresistant generalized epilepsy syndromes. Seizure 2004;13:340-345.

100. Huf RL, Mamelak A, Kneedy-Cayem K. Vagus nerve stimulation therapy: 2-year prospective open-label study of 40 subjects with refractory epilepsy and low IQ who are living in long-term care facilities. Epilepsy Behav 2005;6:417-423.

101. Rychlicki F, Zamponi N, Trignani R, et al. Vagus nerve stimulation: clinical experience in drug-resistant pediatric epileptic patients. Seizure 2006;15:483-490.
102. Saneto RP, Sotero de Menezes MA, Ojemann JG, et al. Vagus nerve stimulation for intractable seizures in children. Pediatr Neurol 2006;35:323-326.

103. Ardesch JJ, Buschman HP, Wagener-Schimmel LJ, et al. Vagus nerve stimulation for medically refractory epilepsy: a long-term follow-up study. Seizure 2007;16:579-585.

104. De Herdt V, Boon P, Ceulemans B, et al. Vagus nerve stimulation for refractory epilepsy: a Belgian multicenter study. Eur J Paediatr Neurol 2007;11:261-269.

105. Kostov H, Larsson PG, Roste GK. Is vagus nerve stimulation a treatment option for patients with drug-resistant idiopathic generalized epilepsy? Acta Neurol Scand Suppl 2007;187: $55-58$.

106. Amar AP, Apuzzo ML, Liu CY. Vagus nerve stimulation therapy after failed cranial surgery for intractable epilepsy: results from the vagus nerve stimulation therapy patient outcome registry. Neurosurgery 2008;62(suppl 2):506-513.

107. Rossignol E, Lortie A, Thomas T, et al. Vagus nerve stimulation in pediatric epileptic syndromes. Seizure 2009;18:34-37. 